Check for updates

Cite this: RSC Adv., 2017, 7, 23309

Received 5th April 2017

Accepted 19th April 2017

DOI: $10.1039 / \mathrm{c} 7 \mathrm{ra03891g}$

rsc.li/rsc-advances

\section{Crown ether-containing polyimides with high dielectric constant $\dagger$}

\author{
Ting Yang, Wenhui Xu, Xinwen Peng and Haoqing Hou (D)*
}

Polyimides (PIs) as a dielectric material have attracted much attention due to their good mechanical properties and thermal stability. However, the low dielectric constant of traditional PIs greatly restricts their applications in dielectric capacitors. Here we introduce crown ether groups into PI to increase the polarization of molecular chains. The resultant crown ether-containing PI films showed high dielectric constant and low dielectric loss, but without sacrificing the mechanical and thermal properties.

\section{Introduction}

Polyimides (PIs) are well-known for their good thermal stability, excellent mechanical properties, easy formation and molecular structure tuneable properties, and are widely used in various fields (aerospace, photonic applications, composites, filtration and electronics).$^{1-7}$ However, due to the poor polarization of their rigid molecular structures, PIs usually possess a relatively low dielectric constant (2.5-3.5), which greatly limits their applications as high dielectric materials. ${ }^{\mathbf{1 , 8}}$ Many studies have incorporated inorganic fillers (with high dielectric constant) and conductive fillers into the PI matrix to increase the dielectric constant. ${ }^{9-13}$ For example, 50 vol\% of $\mathrm{BaTiO}_{3}$ can lead to the increase of dielectric constant to $29,{ }^{14}$ while $20 \mathrm{vol} \%$ addition of MWCNT increased the dielectric constant even to $217 .^{15}$ However, the large amount addition of inorganic fillers would sacrifice the mechanical properties especially toughness of the PI matrix while the addition of conductive fillers led to the increase of dielectric loss. ${ }^{16-18}$ On the other hand, the PI-based composites usually have drawbacks of filler aggregation, phase separation, and the increased densities. Another strategy to improve the dielectric properties of PI is to increase the polarization of PI molecular chains. For example, Peng et al. incorporated metals ( $\mathrm{Yb}$ and $\mathrm{Cu}$ ) to complex PI molecules containing bipyrimidine or bipyridine units. ${ }^{19,20}$ Because of the increased polarity from the incorporation of metals, the obtained PI-metal complexes achieved high dielectric constant of more than 100. However, the synthesis of the bipyrimidine- or bipyridine-containing diamine monomer was too complicated and time consuming. Moreover, because of the low activity of the bipyrimidine- or bipyridine-containing diamine monomer, the resulted PI precursor, polyamic acid (PAA), was difficult to

Department of Chemistry and Chemical Engineering, Jiangxi Normal University, Nanchang, 330022, China.E-mail: haoqing@jxnu.edu.cn

† Electronic supplementary information (ESI) available. See DOI: 10.1039/c7ra03891g attain high molecular weight, which led to the relatively low mechanical and thermal properties. Therefore, it is still a challenge to develop PIs with high dielectric constants without compromising other key characteristics, such as mechanical properties, thermal properties and uniform film formation.

In this work, crown ether-containing diamine monomer was synthesized in a facile way and used to prepare crown ethercontaining PI films. Due to the multiple ether polar groups in the main chains of PI molecules, the PI films are expected showing much higher dielectric constants than that of PIs without crown ether group. Moreover, the crown ethercontaining PI films can still maintain their good mechanical property and thermal stability. Thus, these PIs would be promising dielectric materials toward polymer film capacitors in high temperature fields.

\section{Experimental}

The synthesis of crown ether-containing diamine monomer, characterizations of chemical structure of monomer, preparation of crown ether-containing PIs, and measurements were included in ESI. $\dagger$ The whole procedure for the preparation of crown ether-containing PIs was shown in Scheme 1.

\section{Results and discussion}

Scheme 1 presents the synthesis of crown ether-containing diamine monomer by two simple reactions of nitration reaction and reduction reaction. Proton nuclear magnetic resonance spectra $\left({ }^{1} \mathrm{H}-\mathrm{NMR}\right)$, FTIR spectra, and element analysis confirmed the successful preparation of the diamine monomer $($ ESI $\dagger$ ). Fig. 1 shows the FTIR spectra of PAAs and PIs. Both PAAs and PIs exhibited the characteristic absorptions at $2942 \mathrm{~cm}^{-1}$ and $2853 \mathrm{~cm}^{-1}$ (C-C stretching), $1254 \mathrm{~cm}^{-1}$ (Ar-O-R stretching), $1124 \mathrm{~cm}^{-1}$ (C-O-C stretching), which proved the existence of crown ether groups in PAAs and PIs. The characteristic absorptions of PAAs were observed at $1715 \mathrm{~cm}^{-1}(\mathrm{C}=\mathrm{O}$ 

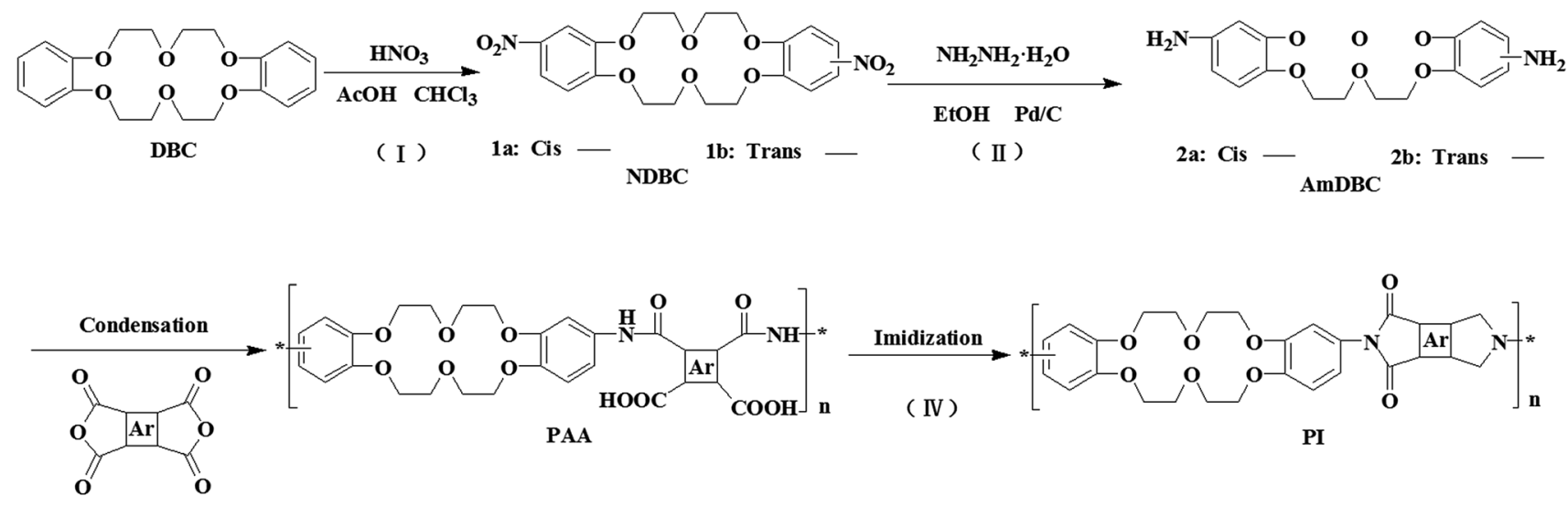

( III)<smiles>Cc1ccc(-c2ccc(C)c(Br)c2)cc1C</smiles>

(PI-a)<smiles>Cc1ccc(C(=O)c2ccc(C)c(C)c2)cc1C</smiles>

(PI-b)

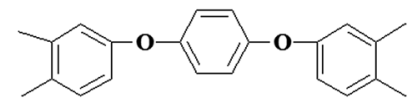

(PI-c)

Scheme 1 Procedure of the synthesis of crown ether-containing PAAs and PIs. The reagents and conditions are described as follows: (I) NDBC: chloroform, glacial acetic acid, nitrating solution, heating at $50{ }^{\circ} \mathrm{C}$ for $5 \mathrm{~h}$; (II) $\mathrm{AmDBC}$ : $\mathrm{NH}_{2} \mathrm{NH}_{2}, \mathrm{EtOH}, \mathrm{Pd} / \mathrm{C}$, heating at $50{ }^{\circ} \mathrm{C}$ for $2 \mathrm{~h}$; (III) PAA: DMAc, $0{ }^{\circ} \mathrm{C}$ for $24 \mathrm{~h}$; (IV) PI: heating to $150{ }^{\circ} \mathrm{C}$ at a rate of $5^{\circ} \mathrm{C} \mathrm{min}^{-1}$, annealing for $1 \mathrm{~h}$ to remove the residual solvent, then heating at a rate of $2{ }^{\circ} \mathrm{C}$ $\mathrm{min}^{-1}$ and annealing at $250^{\circ} \mathrm{C}$ for $1 \mathrm{~h}$, finally heating at a rate of $4^{\circ} \mathrm{C} \mathrm{min}-1$ and annealing at $300{ }^{\circ} \mathrm{C}$ in for $2 \mathrm{~h}$.

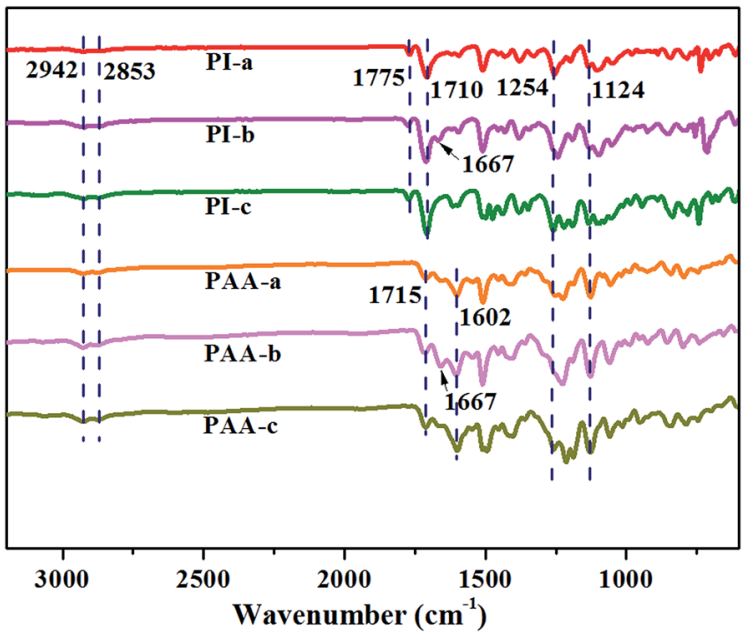

Fig. 1 FTIR spectra of PAA and PI films.

stretching in the group $-\mathrm{COOH})$ and $1602 \mathrm{~cm}^{-1}(\mathrm{C}=\mathrm{O}$ stretching in the group - $\mathrm{CONH}-$ ). After high temperature imidization, the peaks at 1715 and $1602 \mathrm{~cm}^{-1}$ disappeared completely while three new peaks at $1775 \mathrm{~cm}^{-1}(\mathrm{C}=\mathrm{O}$ in the imide ring, asymmetric stretching vibration), $1710 \mathrm{~cm}^{-1}(\mathrm{C}=\mathrm{O}$, symmetric stretching vibration in the imide ring) and the appears at $725-732 \mathrm{~cm}^{-1}$ (imide ring deformation) appeared, confirming that PAAs thermally converted into PIs. ${ }^{14}$ It is noteworthy that the peak appears at $1667 \mathrm{~cm}^{-1}$ in spectra of PI-b and PAA-b, which was not observed in other samples. This peak could be attributed to the stretching of carbonyl group in Ar$\mathrm{CO}-\mathrm{Ar}$ derived from ketone dianhydride.

\section{Dielectric properties}

Depending on the chemical structures, PIs possess different dielectric constant. For example, PIs derived from PMDA/ODA, BPDA/ODA and 6FDA-ODA showed dielectric constants of 2.95, 3.10 , and 2.78 at $1 \mathrm{kHz}$ respectively. ${ }^{21}$ Such low dielectric constant could be because the poor polarization of the PI molecular chains. In this work, via molecular structure design, PIs containing crown ether-group was prepared. The introduction of crown ether-group on the PI main chains increased the polarization and led to the dielectric constant increasing to 5.46.9 at frequency range of $100 \mathrm{~Hz}$ to $100 \mathrm{kHz}$ (Fig. 2, Table 1), which was much higher than the neat PI without crown ethergroups (approx. 3.4). ${ }^{8,22}$ In the meantime, crown ethercontaining PIs also displayed quite low dielectric loss $<0.03$ (Fig. 2) in the frequency range of $100 \mathrm{~Hz}$ to $100 \mathrm{kHz}$. This

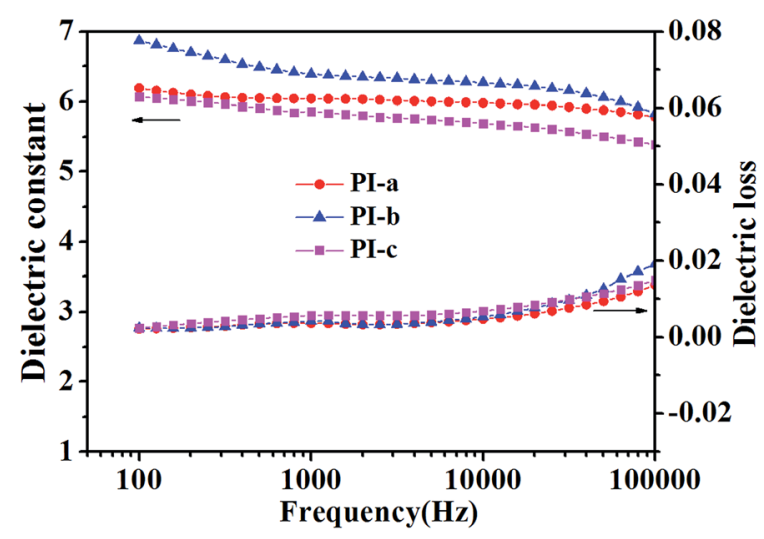

Fig. 2 Dielectric constant and dielectric loss of PI films. 
Table 1 Dielectric, mechanical and thermal properties of crown ether-containing PI films

\begin{tabular}{|c|c|c|c|c|c|c|c|c|}
\hline PIs & Density $\left(\mathrm{g} \mathrm{cm}^{-3}\right)$ & \multicolumn{3}{|c|}{ Dielectric constant } & Strength (MPa) & Strain (\%) & $T_{5 \%}\left({ }^{\circ} \mathrm{C}\right)$ & $T_{\mathrm{g}}\left({ }^{\circ} \mathrm{C}\right)$ \\
\hline PI-b & 1.37 & 6.9 & 6.4 & 6.3 & 126.5 & 10.6 & 423.1 & 341.6 \\
\hline PI-c & 1.35 & 6.1 & 5.9 & 5.7 & 110.8 & 13.6 & 432.2 & 343.1 \\
\hline
\end{tabular}

dielectric loss was quite smaller than that of the PI composites with conductive fillers, such as MWCNTs, ${ }^{15}$ and PANi@CNT fillers. ${ }^{23}$

The molecular structure of the polymer can affect the dielectric constant of the polymer. Higher polarity of polymer has, larger dielectric constant achieves. ${ }^{24}$ Under the action of external electric field, the internal charge of crown ether polyimide molecule will be unevenly distributed, since crown ether polyimide contains a plurality of $-\mathrm{C}-\mathrm{O}-$ bond, which made the polymer more easily polarized. Therefore, the dielectric constant of crown ether polyimide is increased. It is worth noting that the PI-b possess higher dielectric constant than PI$\mathrm{a}$ and PI-c. The possible reason may be that keto bond and the big $\pi$ bond of benzene in PI-b molecular chains, constitute a conjugated structure, which is conducive to the $\pi$ electron motion. Therefore, the delocalized $\pi$ electrons are more easily polarized, which improved the molecular polarization ability of PI-b and dielectric constant. ${ }^{25,26}$

A good mechanical performance is of great importance and necessity for a broad range of applications to high dielectric permittivity materials. In general, tensile testing is an effective method of measuring mechanical properties. The mechanical properties of crown ether polyimide films are showed in Fig. 3 and insert photo exhibited the flexibility of the PI films (thicknesses of PI-a: $32 \mu \mathrm{m}$, PI-b: $22 \mu \mathrm{m}$ and PI-c: $16 \mu \mathrm{m}$ ). All crown ether PI films showed excellent flexibility and strength with tensile strength higher than $111 \mathrm{MPa}$ and elongation at break of more than $9.8 \%$. Moreover, the maximum achievable tensile strength and elongation at break are $147.1 \mathrm{MPa}$ and $13.6 \%$,

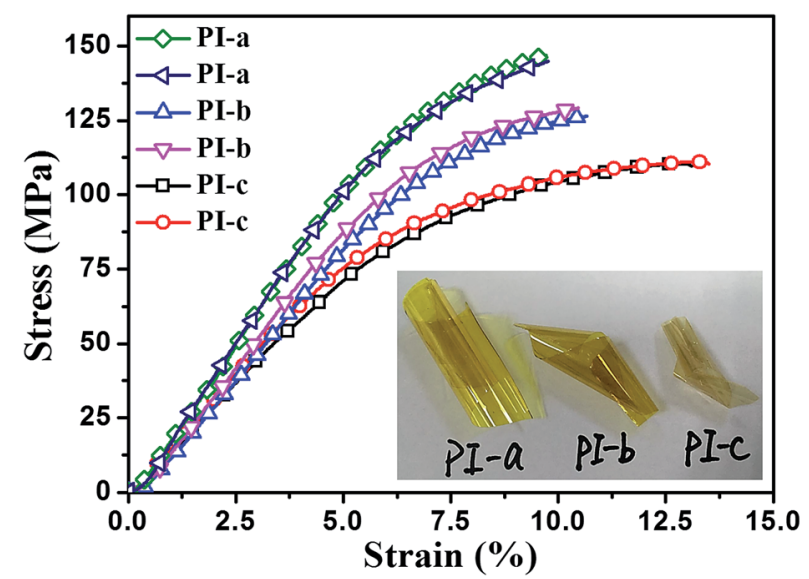

Fig. 3 Stress-strain curves of PI films. Inset is a digital photo of flexible crown ether-containing PI films. respectively. The properties are sufficient to meet the requirements of dielectric layers in capacitors and inductors to high dielectric permittivity material. Experimental results show that the tensile strength and elongation at break of PIs would be gradually decreased, when the rigid of dianhydride monomer was become weaken. The mechanical properties of the polymers is depending on the strength of the molecular chain (the molecular chain respond to outside forces) and the strength of the molecular is affected by some parameters, such as the chemical structure, the spatial configuration and the outside forces. We believe that the multiple ether bonds and the polarity of oxygen atoms, present in the PI macromolecule, can be attributed to the excellent mechanical properties. These PI films with excellent mechanical properties made them good candidates for application in high-tech electronic fields.

TGA is usually used to characterize the thermal stabilities of materials. It could be seen that all the PIs display high onset decomposition temperature, and the temperature of $5 \%$ weight
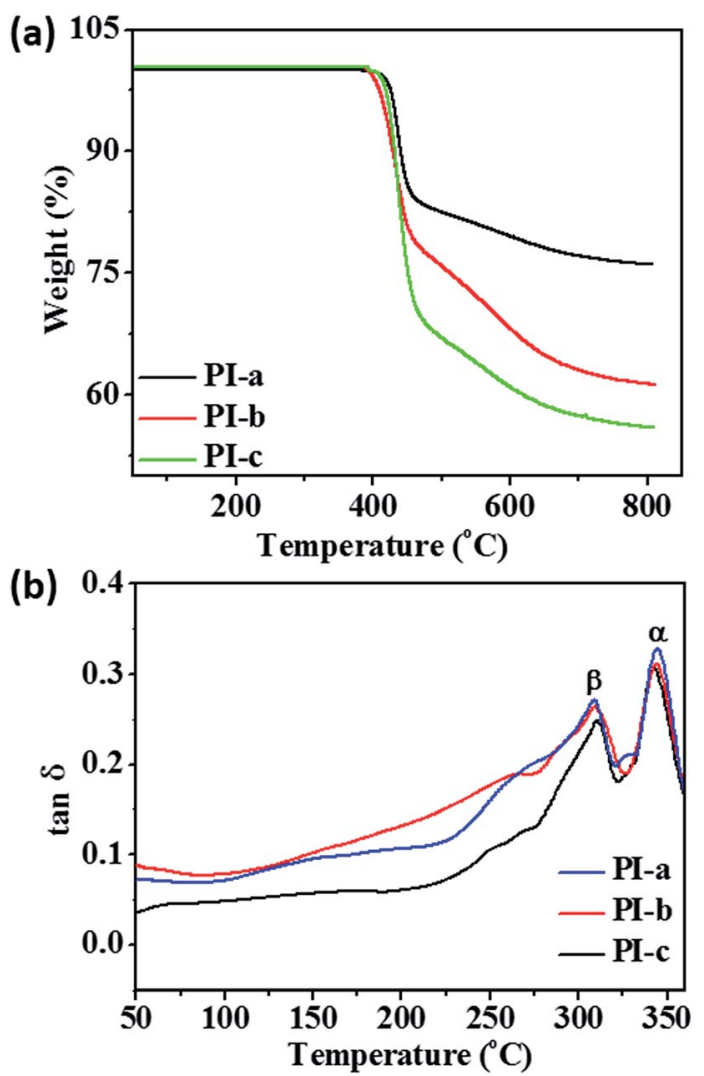

Fig. 4 TGA and DMA curves of PI films. 
loss was located at $415-432{ }^{\circ} \mathrm{C}$ (Fig. $4 \mathrm{a}$, Table 1 ), suggesting that the PIs possess good thermal stability and high heat resistance. Additionally, glass transition temperature $\left(T_{\mathrm{g}}\right)$ is an important parameter to assess the continuous use temperature of materials. Generally, dynamic mechanical analysis (DMA) and differential scanning calorimetry (DSC) are used to determine the $T_{\mathrm{g}}$ of polymer. However, there are no obvious signals in DSC, when the energy of polymer isn't changed much with the glass state converting high elastic state. Therefore, dynamic mechanical analysis (DMA) is more efficient to measure the $T_{\mathrm{g}}$ of those materials (such as PI). As shown in Fig. 4b and Table 1, the DMA curves of PIs contained two main peaks of peak $\alpha$ and peak $\beta$ (Fig. 4b). The peak $\alpha$ could at $341-343{ }^{\circ} \mathrm{C}$ could be attributed to the $T_{\mathrm{g}}$ of PI films, which was much higher than the bipyrimidine-containing PIs $\left(291{ }^{\circ} \mathrm{C}\right),{ }^{19}$ bipyridine-containing PIs $\left(285{ }^{\circ} \mathrm{C}\right),{ }^{20}$ and pyrimidine-containing co-PIs $\left(262{ }^{\circ} \mathrm{C}\right) .{ }^{27}$ Due to the large amount of crown ether-groups, the PI molecular chains also exhibited a secondary kinetic movements, which led to the appearance of the peak $\beta$.

\section{Conclusions}

PI films, containing crown ether-units, were successfully prepared from the crown ether-containing diamine (AmDBC) and dianhydride (s-BPDA, BTDA, HQDA) via a two-step method. The PI films possess excellent dielectric properties with high dielectric constant (5.8-6.4), low dielectric loss $(<0.03)$ at the frequency ranged from 100 to $100 \mathrm{kHz}$. In addition, the high dielectric constant and low dielectric loss were achieved without sacrificing other key properties, such as thermal stabilities and mechanical properties. The crown ether containing PI films have high glass transition temperature $\left(341-343{ }^{\circ} \mathrm{C}\right)$ and decomposition temperature of up to $415-432{ }^{\circ} \mathrm{C}$. The PI also possess excellent mechanical properties (with a tensile strength of 110.8-147.1 MPa and elongation at break of 9.8-13.6\%). The excellent properties were attributed to the introduction large amount of crown ether moieties in the PI macromolecular chains. Such PI films show a promising application in polymer film capacitors in high temperature fields.

\section{Acknowledgements}

The authors are indebted to National Natural Science Foundation of China (Grants No. 21374044 and 51563012) for financial support.

\section{Notes and references}

1 M. Ding, Prog. Polym. Sci., 2007, 32, 623-668.

2 Y. Ding, H. Hou, Y. Zhao, Z. Zhu and H. Fong, Prog. Polym. Sci., 2016, 61, 67-103.

3 S. Jiang, H. Hou, S. Agarwal and A. Greiner, ACS Sustainable Chem. Eng., 2016, 4, 4797-4804.
4 S. Jiang, G. Duan, J. Schöbel, S. Agarwal and A. Greiner, Compos. Sci. Technol., 2013, 88, 57-61.

5 Y. He, D. Han, J. Chen, Y. Ding, S. Jiang, C. Hu, S. Chen and H. Hou, RSC Adv., 2014, 4, 59936-59942.

6 S. Jiang, G. Duan, L. Chen, X. Hu, Y. Ding, C. Jiang and H. Hou, New J. Chem., 2015, 39, 7797-7804.

7 S. Jiang, G. Duan, L. Chen, X. Hu and H. Hou, Mater. Lett., 2015, 140, 12-15.

8 Q. Chi, J. Sun, C. Zhang, G. Liu, J. Lin, Y. Wang, X. Wang and Q. Lei, J. Mater. Chem. C, 2014, 2, 172-177.

9 S.-H. Xie, B.-K. Zhu, X.-Z. Wei, Z.-K. Xu and Y.-Y. Xu, Composites, Part A, 2005, 36, 1152-1157.

10 W. Xu, Y. Ding, S. Jiang, L. Chen, X. Liao and H. Hou, Mater. Lett., 2014, 135, 158-161.

11 Z.-M. Dang, Y.-Q. Lin, H.-P. Xu, C.-Y. Shi, S.-T. Li and J. Bai, Adv. Funct. Mater., 2008, 18, 1509-1517.

12 Y. Yang, H. Sun, D. Yin, Z. Lu, J. Wei, R. Xiong, J. Shi, Z. Wang, Z. Liu and Q. Lei, J. Mater. Chem. A, 2015, 3, 4916-4921.

13 W. Xu, Y. Feng, Y. Ding, S. Jiang, H. Fang and H. Hou, Mater. Lett., 2015, 161, 431-434.

14 W. Xu, Y. Ding, S. Jiang, W. Ye, X. Liao and H. Hou, Polym. Compos., 2016, 37, 794-801.

15 Q. Chen, W. Wu, Y. Zhao, M. Xi, T. Xu and H. Fong, Composites, Part B, 2014, 58, 43-53.

16 Y. Yang, Z. Wang, Y. Ding, Z. Lu, H. Sun, Y. Li, J. Wei, R. Xiong, J. Shi, Z. Liu and Q. Lei, APL Mater., 2013, 1, 050701.

17 Y. Yang, B.-P. Zhu, Z.-H. Lu, Z.-Y. Wang, C.-L. Fei, D. Yin, R. Xiong, J. Shi, Q.-G. Chi and Q.-Q. Lei, Appl. Phys. Lett., 2013, 102, 042904.

18 Y. Yang, H. Sun, B. Zhu, Z. Wang, J. Wei, R. Xiong, J. Shi, Z. Liu and Q. Lei, Appl. Phys. Lett., 2015, 106, 012902.

19 X. Peng, Q. Wu, S. Jiang, M. Hanif, S. Chen and H. Hou, Mater. Lett., 2014, 133, 240-242.

20 X. Peng, W. Xu, L. Chen, Y. Ding, S. Chen, X. Wang and H. Hou, J. Mater. Chem. C, 2016, 4, 6452-6456.

21 C. Lee, Y. Shul and H. Han, J. Polym. Sci., Part B: Polym. Phys., 2002, 40, 2190-2198.

22 P. Thiruvasagam and B. Saritha, J. Polym. Res., 2015, 22, 86. 23 W. Xu, Y. Ding, Y. Yu, S. Jiang, L. Chen and H. Hou, Mater. Lett., 2017, 192, 25-28.

24 J. Kułek, C. Pawlaczyk and E. Markiewicz, J. Electrost., 2002, 56, 135-141.

25 H. A. Pohl and R. Pethig, J. Phys. E: Sci. Instrum., 1977, 10, 190.

26 L. C. Dunn, W. T. Ford, N. Hilal, P. S. Vijayakumar and H. A. Pohl, J. Polym. Sci., Polym. Phys. Ed., 1984, 22, 22432260.

27 L. Chen, S. Jiang, J. Chen, F. Chen, Y. He, Y. Zhu and H. Hou, New J. Chem., 2015, 39, 8956-8963. 